\title{
Modelling the effects of chlorophyll fluorescence from subsurface layers on photosynthetic efficiency measurements in microphytobenthic algae
}

\author{
Rodney M. Forster*, Jacco C. Kromkamp \\ Netherlands Institute of Ecology (NIOO-KNAW), Centre for Estuarine and Marine Ecology, Korringaweg 7, 4401 NT Yerseke,
} The Netherlands

\begin{abstract}
Irradiance is attenuated rapidly in benthic microalgal mats. This makes it difficult to quantify the relevant light field for the benthic community, which is a necessary parameter for accurate primary production estimates. Photosynthesis of microphytobenthos on estuarine mudflats can be measured using variable fluorescence techniques and can be expressed as relative linear photosynthetic electron transport (rETR) by multiplying the effective PSII photochemical efficiency $\left(\Delta F / F_{\mathrm{m}}{ }^{\prime}\right)$ with the incident photon irradiance $(E)$ impinging on the sediment surface. An assumption of the method is that the measured chlorophyll fluorescence signal is proportional to the inherent photosynthetic properties of the microalgal assemblage at any particular irradiance. However, contribution of upwelling fluorescence from algae present beneath the surface, originating at an irradiance lower than the surface irradiance, may distort the relationship. An optical model was constructed in order to test the relationship between inherent and apparent fluorescence responses from simulated intertidal sediments. The model uses a detailed description of microphytobenthic pigmentdepth profiles in order to create a realistic simulation of the within-sediment irradiance field. The variable fluorescence yield measured by an instrument at the sediment surface overestimated the inherent yield by more than $20 \%$ at high irradiance. The largest overestimates of up to $60 \%$ were found in an extreme case of an algal cell layer positioned 100 to $150 \mu \mathrm{m}$ below the sediment surface but the overestimation was, in most cases, in the range of 20 to $40 \%$, with relatively little difference between sediments of different pigment profiles. Primary production was also estimated from the model using fluorescence-based parameters alone. For the sediment types most commonly found in the field situation, modeled production and calculated total production of the sediment were found to show a linear correlation, thus justifying the use of the variable fluorescence method in estimation of this important ecosystem function.
\end{abstract}

KEY WORDS: Microphytobenthos · Sediment irradiance field · Photic depth · Quantum efficiency · PSII $\cdot$ Photosynthesis $\cdot$ Chlorophyll fluorescence $\cdot$ Non-photochemical quenching

Resale or republication not permitted without written consent of the publisher

\section{INTRODUCTION}

The rate of photosynthesis of plants depends primarily on 2 factors: the overall quantum efficiency of the photosynthetic process and the rate of light absorption (Kirk 1994). This latter process is the combination of absorption of light by the photosynthetic pigments and the irradiance available. For an accurate measurement of the rate of photosynthesis, the light field should thus be known, requiring careful measurement of incident irradiance. This is by no means a trivial matter. Irradiance intercalibration exercises have shown large variability in readings (Jewson et al. 1984), perhaps due to infrequent calibration of sensors against a primary standard. In phytoplankton production studies with an incubator (Colijn et al. 1996) or photosynthetron (Lewis \& Smith 1983), the irradiance to which an algal suspension is exposed during a photosynthesis-irradiance 
(P-E) curve can be measured relatively accurately by placing a small spherical sensor in the vial or bottle used to incubate the samples, although operator bias can still be a problem (Meyercordt et al. 1999). With natural phytoplankton samples, the light gradient within the vessels of the incubator is often negligible because of the low biomass. Global comparisons of P-E parameters between different users can, therefore, be made with reasonable confidence (Behrenfeld \& Falkowski 1997).

Microphytobenthic algae have great ecological importance in estuarine and coastal marine ecosystems but assessing the primary production of sedimentdwelling benthic microalgal assemblages can be difficult. Suspensions of microphytobenthic samples may often contain large amounts of sediments, causing a steep light gradient within the vial or cuvette (Wolfstein et al. 2000) and the quantification of the actual light field experienced by the algae becomes more complex. However, microphytobenthos photosynthesis can also be measured in situ on intact sediments with the variable fluorescence method (Kromkamp et al. 1998). Quantification of the incident irradiance at a flat sediment surface should, in principle, be simpler than the measurement of irradiance in a turbid suspension. The variable fluorescence method measures linear electron transport by photosystem II (PSII), which can be used with caution to estimate rates of oxygen evolution (see discussion in Masojídek et al. 2001). Electron transport rate or ETR equals the product of apparent or effective photochemical efficiency $\Delta F / F_{\mathrm{m}}$ ' (Genty et al. 1989), the optical cross-section of PSII (a $\left.a_{\mathrm{PSII}}\right)$ and the incident irradiance $(E)$ : $\mathrm{ETR}=\Delta F / F_{\mathrm{m}}{ }^{\prime} \times a_{\mathrm{PSII}} \times E$. As $a_{\mathrm{PSII}}$ is difficult to measure, ETR can also be expressed in relative form: $\mathrm{rETR}=\Delta F / F_{\mathrm{m}}{ }^{\prime} \times E$ (Hofstraat et al. 1994, Flameling \& Kromkamp 1998, Kromkamp et al. 1998).

The effective photochemical efficiency, $\Delta F / F_{\mathrm{m}}{ }^{\prime}$, is a sensitive measure of the photosynthetic apparatus, immediately responsive to changes in the irradiance field and to environmental effects such as temperature change (Morris \& Kromkamp 2003). Its measurement, and the calculation of rETR, is deceptively simple, and the development of compact, modulated fluorometers and irradiance sensors has stimulated the application of the chlorophyll fluorescence method in almost every aquatic environment (Glud et al. 2002, Kromkamp \& Forster 2003).

However, there are known to be steep irradiance gradients within photosynthetic tissues (Vogelmann \& Evans 2002) and also within marine sediments (Kühl \& Jørgensen 1994, Decho et al. 2003). The penetration depth of a fluorometer measuring beam within the photic zone of sediment-algae matrix may be variable, implying that the measurement of $E$ and $\Delta F / F_{\mathrm{m}}{ }^{\prime}$ at the surface of the sediment should be performed with cau- tion. The 'measuring depth' of a typical pulse-amplitude modulation (PAM)-type portable fluorometer (Schreiber et al. 1994) has been estimated to be 150 to $200 \mu \mathrm{m}$ into the sediment (Kromkamp et al. 1998, Serôdio et al. 2001) but this is difficult to verify and, in any case, will depend on the optical properties of the sediment. As $\Delta F / F_{\mathrm{m}}{ }^{\prime}$ increases when irradiance decreases (with depth), there will be a steep vertical gradient in effective PSII photochemical efficiency in the sediment. The signal of the effective photochemical efficiency arising from deep within the sediment will be significantly higher than that derived from cells exposed at the surface. Any contribution by upward fluorescence to the signal measured at the sediment surface will cause an overestimation of the $\Delta F / F_{\mathrm{m}}{ }^{\prime}$ measured and thus, the ETR calculated. Mass downward migration of microalgal cells away from the sediment surface, to a lower position in the irradiance gradient, will also increase the effective photochemical efficiency observed with a fluorometer at the surface. This is a potential problem that led Perkins et al. (2002) to question the validity of results obtained with the variable fluorescence method.

It is the aim of this paper to quantify the irradiance field associated with the layer in which the fluorescence signal originates and to calculate the value of $\Delta F / F_{\mathrm{m}}{ }^{\prime}$ for a range of different scenarios. Our main objective is to prove that the photochemical efficiencies measured at the surface can be used to calculate rates of photosynthesis for intact intertidal sediments. With the assumption that the inherent photosynthetic properties do not change with sediment depth, a sediment-irradiance model was developed which describes the cumulative effect of chlorophyll fluorescence from deeper layers on the integral signal measured at the surface by a PAM-type fluorometer. Recent advances in the fine-scale measurement of microalgal depth distributions are included in the model in order to provide an accurate description of the irradiance field within the sediment photic zone. Different combinations of chlorophyll-depth profiles are used to simulate natural events such as vertical migration and biofilm formation. Attenuation coefficients for biological and non-biological material are treated separately, and the induction of fluorescence quenching under high light was tested. The results were analysed and model calculations are compared with estimates of sediment primary production.

\section{MATERIALS AND METHODS}

A sediment optical model was constructed to calculate the amount of chlorophyll fluorescence detectable at the sediment surface as a function of irradiance, 
physiological status and depth distribution of cells. The model used known depth profiles of microphytobenthic chlorophyll (chl a) as well as physiological and optical parameters from our own studies and from the literature. The heterogeneous distribution of chlorophyll with depth is described explicitly with a depth resolution of $10 \mu \mathrm{m}$, and attenuation coefficients for the microalgal component and for the sediment matrix were calculated separately for each depth interval, as described below.

Simulation of microphytobenthic chlorophyll profiles with depth. Recent advances in sampling technology using liquid nitrogen freezing have allowed intact sediments to be sampled with minimal structural disruption (Cryolander technique, Wiltshire et al. 1997). From the resulting frozen cores, the fine-scale depth distribution of microphytobenthic chl a can be quantified by slicing the samples on a freezing cryotome. Subsamples from defined depth intervals, typically $100 \mu \mathrm{m}$ slices, can then be analysed individually for pigment concentration. Kelly et al. (2001) used this technique to measure a depth profile of chl $a$ in a sample from a low shore site in the Eden estuary, Scotland, in September 1997. de Brouwer \& Stal (2001) also measured chl a content on $200 \mu \mathrm{m}$ slices of frozen cores taken during daytime and nighttime low tides from a site in the Westerschelde estuary. Both papers reported a highly skewed distribution of chl a during daytime, with highest concentrations of pigments found at the surface of the sediment. Curves through the data from both papers were fitted using double exponential decreases in pigment with depth (Fig. 1) in order to obtain the closest match to the data.

Both authors reported the values as $\mu \mathrm{g}$ chl a (g sediment dry weight) ${ }^{-1}$. For use in the sediment-optical model, data were converted to volumetric units $\mathrm{mg} \mathrm{chl}$ $a \mathrm{~m}^{-3}$ for each discrete $10 \mu \mathrm{m}$ depth interval using an assumed mean dry bulk sediment density of $0.70 \mathrm{~g}$ $\mathrm{cm}^{-3}$. This was the average value for sediments collected during 2002 to 2003 in the Westerschelde estuary, as well as being a representative value for estuarine sediments with a mud content of $60 \%$ (Flemming \& Delafontaine 2000), and corresponds to a water content of approximately $50 \%$ using the equations of Flemming \& Delafontaine (2000).

For comparison, a uniform chl a profile was also constructed termed 'UNI'. The integrated chl a content of the uniform profile over the depth interval 0 to $2000 \mu \mathrm{m}$ was set to be equal to that of the 'BS' (after de Brouwer \& Stal 2001) profile at $86 \mathrm{mg} \mathrm{chl} \mathrm{a} \mathrm{m}^{-2}$. This value is close to the annual mean chl a concentration for intertidal mudflats in the Westerschelde estuary of $113 \mathrm{mg} \mathrm{m}^{-2}$ (based on a $1 \mathrm{~cm}$ sampling depth; de Jong $\&$ de Jonge 1995). By comparison, the integrated chl a concentration from 0 to $2000 \mu \mathrm{m}$ for 'KY' (after Kelly et

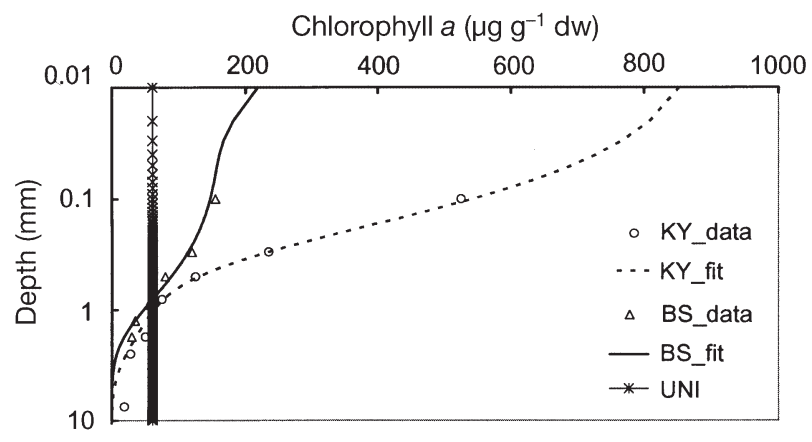

Fig. 1. Distribution of chlorophyll a content $(\mu \mathrm{g}$ chl a [g dry weight $]^{-1}$ ) with depth (logarithmic scale) for 3 of the profiles used in the sediment-optical model. Original data points from Kelly et al. (2001) and de Brouwer \& Stal (2001) are shown as $\mathrm{O}\left({ }^{\prime} \mathrm{KY}\right.$ ') and $\Delta\left({ }^{\prime} \mathrm{BS}\right.$ ') respectively, with lines indicating the modeled best fits. The equations $C h l=4.8 \times \exp ^{(-z \times 0.0055)}+$ $0.81 \times \exp ^{(-z \times 0.0007)}$ and $C h l=1.1 \times \exp ^{(-z \times 0.0010)}+1.02 \times \exp ^{(-z \times}$ ${ }^{0.1045)}$ for the depth profiles of Kelly et al. (2001) and de Brouwer \& Stal (2001), respectively, were used to fit chl a (mg $\mathrm{m}^{-2}$ ) concentrations for discrete depth slices. Chl a content ( $\mu \mathrm{g}$ $\mathrm{g}$ dry weight ${ }^{-1}$ ) was then calculated at each depth interval as described in 'Materials and methods'. A uniform profile ('UNI') is shown for comparison

al. 2001) was $180 \mathrm{mg} \mathrm{m}^{-2}$. This value approaches the upper limit for a well developed diatom community (Underwood \& Kromkamp 1999).

However, the cryolander slicing technique is not fine enough to sample the pigment-depth distribution if the mobile diatom cells have aggregated as a biofilm at the sediment surface and will also underestimate the sediment surface pigment concentration if the surface of the cryosample was not absolutely flat. Low-temperature scanning electron microscope images of undisturbed estuarine biofilms show one to several layers of densely packed diatom cells within a vertical distance of less than $50 \mu \mathrm{m}$ (Taylor \& Paterson 1998). To account for this situation, further chl a profiles were constructed based on a known diatom cell volume and cellular chl a content (e.g. 5.3 pg chl a cell ${ }^{-1}$; de Jong \& Admiraal 1984), and assuming a close packing of cylindrical-shaped diatom cells within the volume of each depth integral. One profile represented the case of a single layer of cells positioned at the sediment surface, as has been proposed recently in a sediment-production model (Guarini et al. 2000). The single cell layer of closely packed diatoms, denoted 'SSL' had a calculated areal chl a concentration of $29 \mathrm{mg} \mathrm{m}^{-2}$ in the model described here, compared to $25 \mathrm{mg} \mathrm{m}^{-2}$ in the model of Guarini et al. (2000).

Two further chl a profiles were constructed, in order to represent the situation in a well-developed biofilm with a maximum chl a concentration. The depthintegrated chl a concentration of the 2 dense biofilm 
Table 1. Summary of chlorophyll-depth profiles used in the model simulations and depth-integrated pigment distributions for selected depth intervals. KY: data from Kelly et al. (2001); BS: data from de Brouwer \& Stal (2001); UNI: uniform profile; MSL: multilayer surface biofilm; SUB: multilayer subsurface biofilm; SSL: surface monolayer

\begin{tabular}{|c|c|c|c|c|c|c|}
\hline \multirow{2}{*}{$\begin{array}{l}\text { Depth } \\
\text { interval } \\
(\mu \mathrm{m})\end{array}$} & \multicolumn{6}{|c|}{$-\mathrm{Chl} a\left(\mathrm{mg} \mathrm{m}^{-2}\right)$} \\
\hline & KY & BS & UNI & MSL & SUB & SSL \\
\hline $0-50$ & 25 & 7 & 2 & 202 & 0 & 29 \\
\hline $0-100$ & 46 & 12 & 4 & 207 & 0 & 29 \\
\hline $0-200$ & 75 & 22 & 8 & 207 & 207 & 29 \\
\hline $0-400$ & 108 & 38 & 17 & 207 & 207 & 29 \\
\hline $0-1000$ & 149 & 67 & 42 & 207 & 207 & 29 \\
\hline $0-2000$ & 180 & 86 & 85 & 207 & 207 & 29 \\
\hline $0-5000$ & 207 & 94 & 213 & 207 & 207 & 29 \\
\hline
\end{tabular}

models was equal and set to the same value as the ' $\mathrm{KY}$ ' model at $207 \mathrm{mg} \mathrm{m}^{-2}$ (Table 1). The maximum abundance of cells was either located as a biofilm consisting of multiple stacked layers of cells at the sediment surface (denoted 'MSL') or was positioned between 100 to $150 \mu \mathrm{m}$ below the surface (denoted 'SUB'). The subsurface biofilm represents a situation in which mobile algal cells have changed their position in the sediment due to migration. Pennate diatom cells are known to show synchronized mass migrations away from the sediment surface in response to their internal biological clock and to environmental stimuli (Round \& Palmer 1966, Serôdio et al. 1997).

Calculation of irradiance profiles for PAR and for the fluorometer measuring light (ML). The photosynthetically active irradiance $\left(E_{\mathrm{PAR}}\right)$ at each depth integral $z$ is determined by the diffuse light attenuation coefficient $k_{\mathrm{d}(\mathrm{sum})}$ and the irradiance leaving the overlying layer $E_{(z-1)}$ :

$$
E_{z, \mathrm{PAR}}=E_{(\mathrm{z}-1, \mathrm{PAR})} \times \mathrm{e}^{-k_{\mathrm{d}(\mathrm{sum})} \times z}
$$

For the uppermost layer of the sediment model, $E_{(z-1)}$ was equal to $E_{(o)}$, the incident surface irradiance. Attenuation was partitioned with separate coefficients for biological and non-biological components of the sediment. In the model, sediment particles and diatoms compete for space within each depth interval according to:

$$
\text { Sed }=1-\frac{(\mathrm{Chl} / \mathrm{Chlcell})}{\text { Vol }} \times \text { Cellvol }
$$

where Sed is the amount of sediment in each depth interval with volume of $\mathrm{Vol}, \mathrm{Chl}$ is the chl a content per depth interval, Chlcell is the cellular chl a content and Cellvol is the volume of a cell.

Sediment particles could be completely replaced by diatoms $(\mathrm{chl} a)$ in the case of the dense biofilms repre- sented in models 'MSL' and 'SUB', which is in agreement with published electron micrographs of sediment surfaces. Attenuation due to non-biological components (comprising inorganic sand and mud grains, and chromophoric organic material) was proportional to the amount of sediment dry weight in each depth interval, Sed. An initial specific attenuation value of $k^{*}$ d(sed) of $0.011 \mathrm{~m}^{2}$ (mg dry weight) $)^{-1}$ was chosen based on recent experimental data for muddy sediments (J. Kromkamp unpubl. data). In the absence of chlorophyll, this gave a depth-integrated attenuation coefficient of $2 \mathrm{~mm}^{-1}$, which is similar to values found previously in non-colonised, wet sediments (Kühl \& Jørgensen 1994). Attenuation by the biological component was such that diatom cells attenuated irradiance in proportion to their pigment content, Chl. The chl aspecific attenuation coefficient $k^{*}{ }_{\mathrm{d}(\mathrm{chl})}$ was initially set to $0.02 \mathrm{~m}^{2}$ (mg chl a) $)^{-1}$ based on the table of values for planktonic diatom cells given in Kirk (1994) and confirmed by our own work on natural microphytobenthos $\left(k^{*}{ }_{d(c h l)}=0.019 \pm 0.004, n=6\right)$. The combined attenuation in each $10 \mu \mathrm{m}$ depth interval was then calculated as:

$$
k_{\mathrm{d}(\text { sum })}=\left(\operatorname{Sed} \times k_{\mathrm{d}(\text { sed })}^{*}\right)+\left(C h l \times k_{\mathrm{d}(\mathrm{chl})}^{*}\right)
$$

Actinic irradiance $\left(E_{\mathrm{PAR}}\right)$ was propagated downwards through the sediment in discrete $10 \mu \mathrm{m}$ steps, using Eq. (1) applied to each depth interval. This gave distinct irradiance-depth profiles for each of the chl a distributions (Fig. 2). 'Light trapping' in highly scattering sands without microphytobenthos can lead to subsurface irradiances having higher values than the surface (Kühl \& Jørgensen 1994, Kühl et al. 1994). However, the presence of pigmented diatom cells causes photons to be mainly absorbed or scattered in the forward direction (Dodds et al. 1999). Irradiance profiles with micro-scale irradiance sensors were made in cohesive

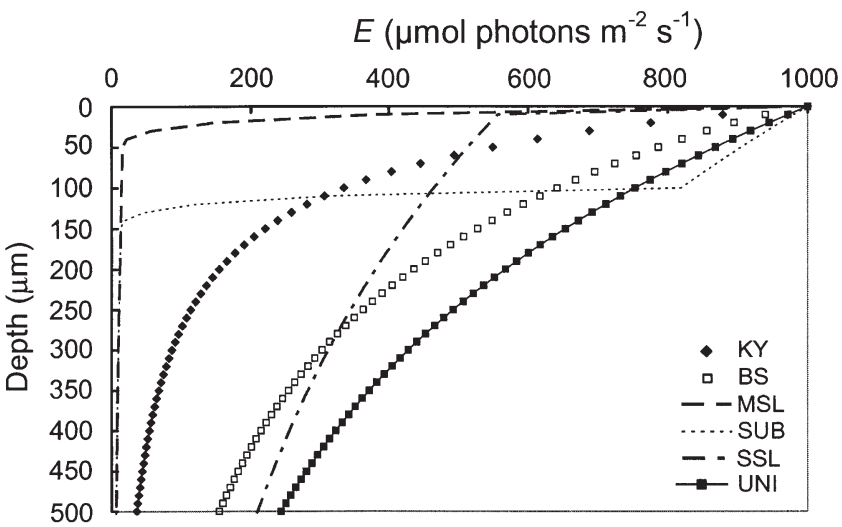

Fig. 2. Calculated profiles of irradiance versus sediment depth for the 6 different distributions of pigment tested in the sediment-optical model 
sediments in the Eden estuary (Scotland), in the Oosterschelde estuary (SW Netherlands) and in the Westerschelde estuary (SW Netherlands) during a previous project: these profiles rarely showed a light trapping effect. This effect was only observed at some very sandy stations with a low algal density (S. F. Hagerthey \& J.C. Kromkamp unpubl. data). Thus, our models differs from a previous sediment optical model proposed by Serôdio et al. (1997) in 2 important ways: irradiance is calculated separately for each depth interval in order to account for the heterogeneous pigment and sediment composition of the individual layers, and enhanced subsurface irradiance due to back-scattering does not occur.

Calculation of chlorophyll fluorescence leaving the sediment surface. The technique for simulating the response of a fluorometer to chlorophyll fluorescence (FL) arising from the sediment surface or within the sediment essentially follows recent work by (Serôdio et al. 1997, Serôdio 2003). The irradiance field defined for each depth layer can now be used to calculate the amount of fluoresced photons produced within the layer and returning to a sensor positioned above the sediment surface. The measuring beam of the fluorometer $\left(E_{\mathrm{ml}}\right)$ is propagated downwards through the sediment using Eq. (1) in the same way as the actinic irradiance.

$$
E_{z(\mathrm{ml})}=E_{(z(\mathrm{ml})-1)} \times \mathrm{e}^{-k_{\mathrm{d}(\mathrm{FL}) \times \mathrm{z}}}
$$

After consideration of a spectral plot of $k_{\mathrm{d}(\mathrm{sum})}$ versus wavelength in Kühl \& Jørgensen (1994), it was decided not to use separate values for $k_{\mathrm{d}(\mathrm{sum})}$ and $k_{\mathrm{d}(\mathrm{FL})}$ in the present model; thus, $k_{\mathrm{d}(\mathrm{FL})}=k_{\mathrm{d}(\mathrm{sum})}$. However, it should be noted that Serôdio et al. (2001) calculated a separate, higher attenuation coefficient for the chlorophyll fluorescence signal compared to that for PAR. The amount of fluorescence generated at each discrete depth was then calculated as being proportional to $E_{(z, \mathrm{ml})} \times C h l_{(\mathrm{z})}$, where $\mathrm{Chl}$ is the microalgal biomass (chl a) present at that particular depth. This term gives the amount of chlorophyll fluorescence which would arise from a target with constant fluorescence efficiency (e.g. a constant ratio of emitted to absorbed photons). However, the fluorescence efficiency of living algal cells is not constant, and varies as a function of environmental and physiological conditions (Krause \& Weis 1991). The yield of fluorescence must, therefore, be calculated as a function of actinic irradiance, photosynthetic rate and physiological status of the cells.

A maximum photosynthetic rate in terms of relative electron transport through photosystem II ( $\left.\mathrm{rETR}_{\max }\right)$ was set as $250 \mathrm{e}^{-} \mathrm{s}^{-1}$ together with an $\alpha_{\mathrm{ETR}}$ (i.e. the initial slope of an rETR/E-curve) of $0.6 \mathrm{e}^{-}$photon $^{-1}$ (Fig. 3). These values represent the 'inherent' photo- physiological responses of the system and are the mean values for sediment suspensions measured during 1999 to 2001 (R. M. Forster unpubl. data). rETR at each depth interval in the hypothetical sediment types was calculated as a function of $E_{(z, \text { par })}$ using Eq. (5) ('target theory'; Webb et al. 1974, Henley 1993) to relate photosynthetic electron flow to irradiance:

$$
\mathrm{rETR}_{z}=\mathrm{rETR}_{\max } \times \mathrm{e}^{\left.-\alpha \cdot \mathrm{E}_{(z, \mathrm{PAR})} / \mathrm{rETR}_{\max }\right)}
$$

The ratio of rETR and $E_{(z, \mathrm{PAR})}$ at each discrete depth gives the photochemical efficiency of photosystem II, $\varnothing_{\mathrm{p}}$, which can also be predicted from measurements of fluorescence via the parameter $\Delta F / F_{\mathrm{m}}{ }^{\prime}$ (Genty et al. 1989):

$$
\varnothing_{\mathrm{p}}=\left(F_{\mathrm{m}}{ }^{\prime}-F\right) / F_{\mathrm{m}}{ }^{\prime}=\Delta F / F_{\mathrm{m}}{ }^{\prime}=\mathrm{rETR} / E_{(z, \mathrm{PAR})}
$$

where $F$ and $F_{\mathrm{m}}$ ' are steady-state and maximum fluorescence parameters (see definitions in Kromkamp \& Forster 2003). The fluorescence yields for $F$ and $F_{\mathrm{m}}{ }^{\prime}$ were calculated at each depth interval by rearranging Eq. (6) and allowing $F_{\mathrm{m}}$ ' to additionally vary as a function of irradiance. $F_{\mathrm{m}}$ was set to 1 at zero irradiance and was reduced by a quadratic function of the form $\left(y=-a E^{2}-b E+1\right)$ as irradiance increased. The quadratic term was inserted to represent the best fit of non-photochemical quenching (NPQ) of chlorophyll fluorescence at high irradiances (Fig. 4), a physiological feature that is particular evident in diatoms (Lavaud et al. 2002). The model was run with different pairs of settings of $a$ and $b$ chosen to represent the range of NPQ values typically found in field samples of microphytobenthos.

Thus, the fluorescence emission at depth $z$ was equal to $E_{(z, \mathrm{ml})} \times \mathrm{Chl}_{(z)} \times F$, where $F$ is the inherent fluorescence efficiency calculated separately for $F$ and $F_{\mathrm{m}}$ '.

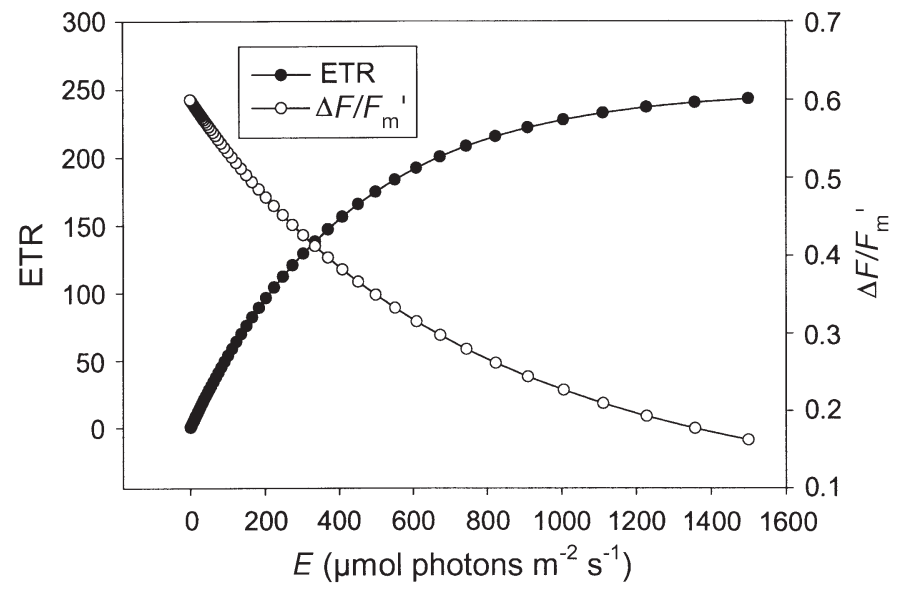

Fig. 3. Photosynthesis versus irradiance curve showing the relationship of ETR and $\Delta F / F_{\mathrm{m}}{ }^{\prime}$ with irradiance $E$ for the input parameters used in the model $\left(\mathrm{ETR}_{\max }=250\right.$ and $\left.\alpha_{\mathrm{ETR}}=0.6\right)$ 


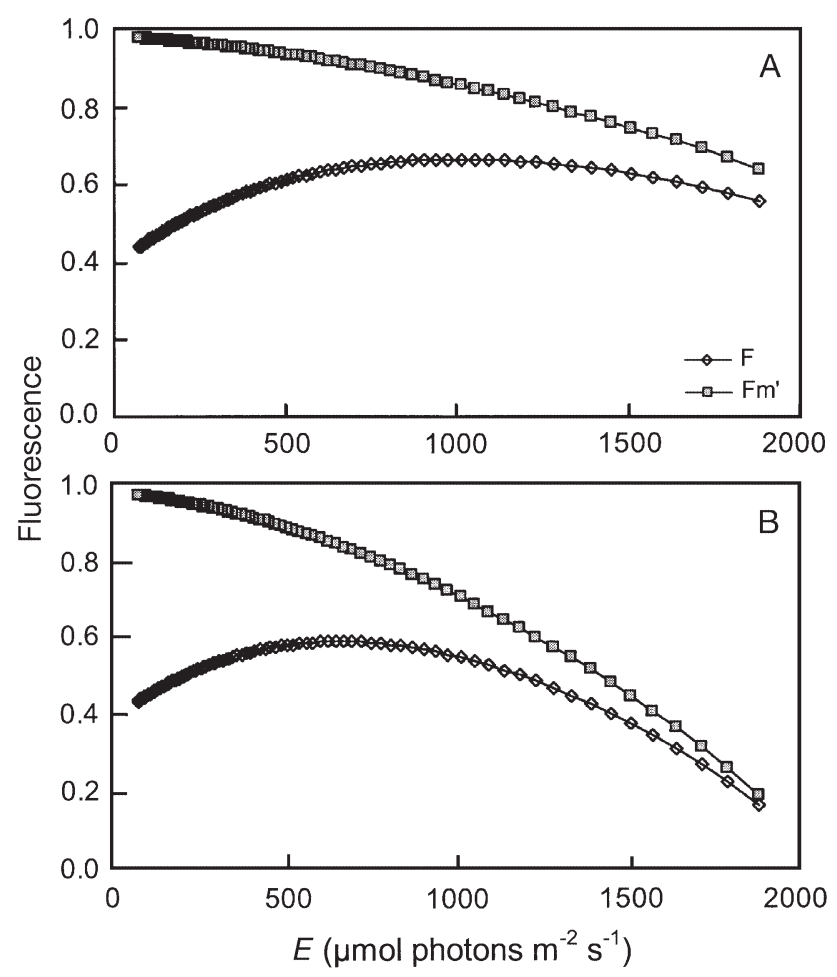

Fig. 4. Effect of non-photochemical quenching (NPQ) on the relative values of the fluorescence parameters $F$ and $F_{\mathrm{m}}{ }^{\prime}$ during exposure to increasing irradiance, $E$. (A) $F$ and $F_{\mathrm{m}}{ }^{\prime}$ calculated with a low level of quenching so that NPQ at the highest irradiance was $<0.1$. (B) $F$ and $F_{\mathrm{m}}{ }^{\prime}$ calculated with a high level of quenching so that NPQ at the highest irradiance was $>4.0$

Finally, the photons emitted at each depth must now return to the surface in order to calculate the apparent or observed fluorescence values (Serôdio et al. 2001). As with the downward flow of photons, the upward flow was calculated separately for each depth interval using Eq. (1) and taking account of changes in $k_{(\mathrm{d}, \text { sum })}$ of the sediment with depth.

The results show the amount of chlorophyll fluorescence arriving at the surface from each depth interval and the integral of fluorescence from all depth intervals gives the signal which would be measured by a modulated fluorometer with capabilities of detecting minimum and maximum fluorescence.

\section{RESULTS}

\section{Modeled light fields}

The irradiance field within the upper sediment was determined by the vertical distribution of pigment. The profiles 'UNI' and 'BS' represented a natural situation in which benthic diatoms are evenly distributed throughout the sediment (e.g. at night) or have migrated to the upper sediment layers (de Brouwer \& Stal 2001). There was an exponential decrease in irradiance with depth when the microalgal chl a was uniformly distributed throughout the sediment ('UNI' profile). A $k_{\mathrm{d}(\mathrm{sum})}$ of $2.8 \mathrm{~mm}^{-1}$ was calculated by linear regression of ln $E$ versus $z$ (Fig. 2, Table 2). The 'BS' model had an approximately equal chl a concentration to 'UNI' over the integral 0 to $2000 \mu \mathrm{m}$ and also had a $k_{\mathrm{d}(\text { sum })}$ of $2.8 \mathrm{~mm}^{-1}$ when calculated over this depth integral. However, because of the skewed chl a distribution, the 'BS' irradiance-depth profile was not exponential in shape and could not be accurately fitted with a single linear regression through all data points. When a series of discrete, narrower depth intervals within the top $2000 \mu \mathrm{m}$ layer were chosen for regression, the resulting attenuation coefficients were larger, e.g. $4.7 \mathrm{~mm}^{-1}$ for the 0 to $50 \mu \mathrm{m}$ depth interval (Table 2). Thus, despite the similar value for $k_{\mathrm{d}(\mathrm{sum}}$, $0-2000$ ), the irradiance field in the upper layers of these 2 sediment types differed considerably. The mean irradiance in the uppermost $400 \mu \mathrm{m}$ was $1200 \mu \mathrm{mol}$ photon $\mathrm{m}^{-2} \mathrm{~s}^{-1}$ for the 'UNI' model and $980 \mu \mathrm{mol}$ photon $\mathrm{m}^{-2} \mathrm{~s}^{-1}$ for 'BS'.

All other non-uniform profiles of chl a with depth gave irradiance profiles which were poorly fitted by linear regression of $\ln E$ versus $z$. Calculation of $k_{\mathrm{d}(\mathrm{sum})}$ with linear regression over the range 0 to $2000 \mu \mathrm{m}$ for the 3 models with highest depth-integrated chl a content produced values of 3.3, 2.2 and $2.5 \mathrm{~mm}^{-1}$ for ' $\mathrm{KY}$ ', 'MSL' and 'SUB', respectively (although none of the regression fits were significant). In these model runs, the calculation of $k_{\mathrm{d}(\mathrm{sum})}$ was strongly dependent on the selection of depth range (Table 2). For the simulation 'MSL', with a dense concentration of diatom cells at the surface of the sediment, a $k_{\mathrm{d}(\text { sum })}$ of $86.8 \mathrm{~mm}^{-1}$ was calculated within the first $50 \mu \mathrm{m}$ depth interval. There was a strong reduction in irradiance within the biofilm, with $98.3 \%$ of the incident irradiance being absorbed

Table 2. Attenuation coefficients $\left(\mathrm{mm}^{-1}\right)$ and photic depth $(\mathrm{mm})$ for selected depth intervals in each of the 6 different input scenarios considered in the sediment-optical model

\begin{tabular}{|c|c|c|c|c|c|c|}
\hline \multirow{2}{*}{$\begin{array}{l}\text { Depth interval } \\
(\mu \mathrm{m})\end{array}$} & \multicolumn{6}{|c|}{$k_{\mathrm{d}}\left(\mathrm{mm}^{-1}\right)$} \\
\hline & $\mathrm{KY}$ & BS & UNI & MSL & SUB & SSL \\
\hline $0-50$ & 12.0 & 4.7 & 2.8 & 86.8 & 2.0 & 10.1 \\
\hline $0-100$ & 10.9 & 4.3 & 2.8 & 40.0 & 2.0 & 4.6 \\
\hline $0-200$ & 9.2 & 4.1 & 2.8 & 14.4 & 29.3 & 2.7 \\
\hline $0-400$ & 7.0 & 3.8 & 2.8 & 5.6 & 14.6 & 2.2 \\
\hline $0-1000$ & 4.4 & 3.3 & 2.8 & 2.6 & 4.6 & 2.0 \\
\hline $0-2000$ & 3.3 & 2.8 & 2.8 & 2.2 & 2.7 & 2.0 \\
\hline $0-5000$ & 2.5 & 2.2 & 2.8 & 2.0 & 2.1 & 2.0 \\
\hline $1 \%$ depth & 1.04 & 1.41 & 1.63 & 1.76 & 0.99 & 2.27 \\
\hline
\end{tabular}


within the algal layer. The simulation of a surface monolayer of cells with the 'SSL' model had a $k_{\mathrm{d}(\mathrm{sum})}$ of $10.1 \mathrm{~mm}^{-1}$ within the upper $50 \mu \mathrm{m}$, resulting in an $48.6 \%$ irradiance decrease after passage through the single layer of cells.

\section{Simulations}

The goal of the modeling exercise was to predict the effect of different optical arrangements of the sediment and associated microalgae on the chlorophyll fluorescence parameters apparent at the surface. A series of simulations were run, each designed to test specific aspects of sediment photobiology. In the first of the simulations, the effect of different surface irradiance conditions on the cumulative fluorescence response was considered.

In darkness, the maximum photochemical efficiency of photosystem II, $\left(F_{\mathrm{m}}-F_{\mathrm{o}}\right) / F_{\mathrm{m}}$, is constant and the relative difference between minimum fluorescence $F_{\mathrm{o}}$ and maximum fluorescence $F_{\mathrm{m}}$ is the same at all depths. Differences in the sediment optical arrangement and parameters do not alter the photochemical yield observed by a modulated fluorometer at the surface, although the absolute levels of $F_{\mathrm{o}}$ and $F_{\mathrm{m}}$ may vary considerably. For estimating the effects of variable surface irradiance, the 'BS' chl a profile was chosen for the initial model runs, as its integrated chl $a$ concentration was representative of the 'average' situation in intertidal estuarine sediments (Underwood \& Kromkamp 1998). The rate of change of algal pigment with depth used in 'BS' was also similar to a published model for pigment distribution in muddy intertidal sediment (Perkins et al. 2003).

The cumulative surface fluorescence for $F$ and $F_{\mathrm{m}}$ ', and the photochemical efficiency $\Delta F / F_{\mathrm{m}}$ ' are shown as functions of increasing depth integration interval for different irradiance scenarios in Fig. 5. In darkness, the cumulative surface fluorescence increases with increasing integration depth for both $F_{\mathrm{o}}$ and $F_{\mathrm{m}}$ until an asymptote is reached (Fig. 5A). Ninety percent of the total fluorescence is derived from the upper $220 \mu \mathrm{m}$ for both $F_{\mathrm{o}}$ and $F_{\mathrm{m}}$, respectively. In terms of chlorophyll, the fluorescence signal for dark-acclimated $F_{\mathrm{o}}$ is derived from the upper $24 \mathrm{mg} \mathrm{m}^{-2}$ of the 'BS' profile or $28 \%$ of the total pigment in the upper $2 \mathrm{~mm}$ of the theoretical core.

Next, surface irradiance was set to $500 \mu \mathrm{mol}$ photon $\mathrm{m}^{-2} \mathrm{~s}^{-1}$. This irradiance was slightly higher than the light saturation point for photosynthesis, which was set in the model to be $E_{\mathrm{k}}=417 \mu \mathrm{mol}$ photon $\mathrm{m}^{-2} \mathrm{~s}^{-1}$. Cumulative fluorescence increased rapidly as integration depth was increased and $90 \%$ of the final signal value for $F$ was reached at a depth of $210 \mu \mathrm{m}$ (Fig. 5B). $\Delta F / F_{\mathrm{m}}{ }^{\prime}$ observed at the surface was not constant but changed as the integration depth was increased. An asymptote for $\Delta F / F_{\mathrm{m}}{ }^{\prime}$ was reached at a shallower depth than $F$ or $F_{\mathrm{m}}{ }^{\prime}$. The $\Delta F / F_{\mathrm{m}}{ }^{\prime}$ value for the uppermost 0 to $10 \mu \mathrm{m}$ layer was 0.355 , which was slightly higher than the
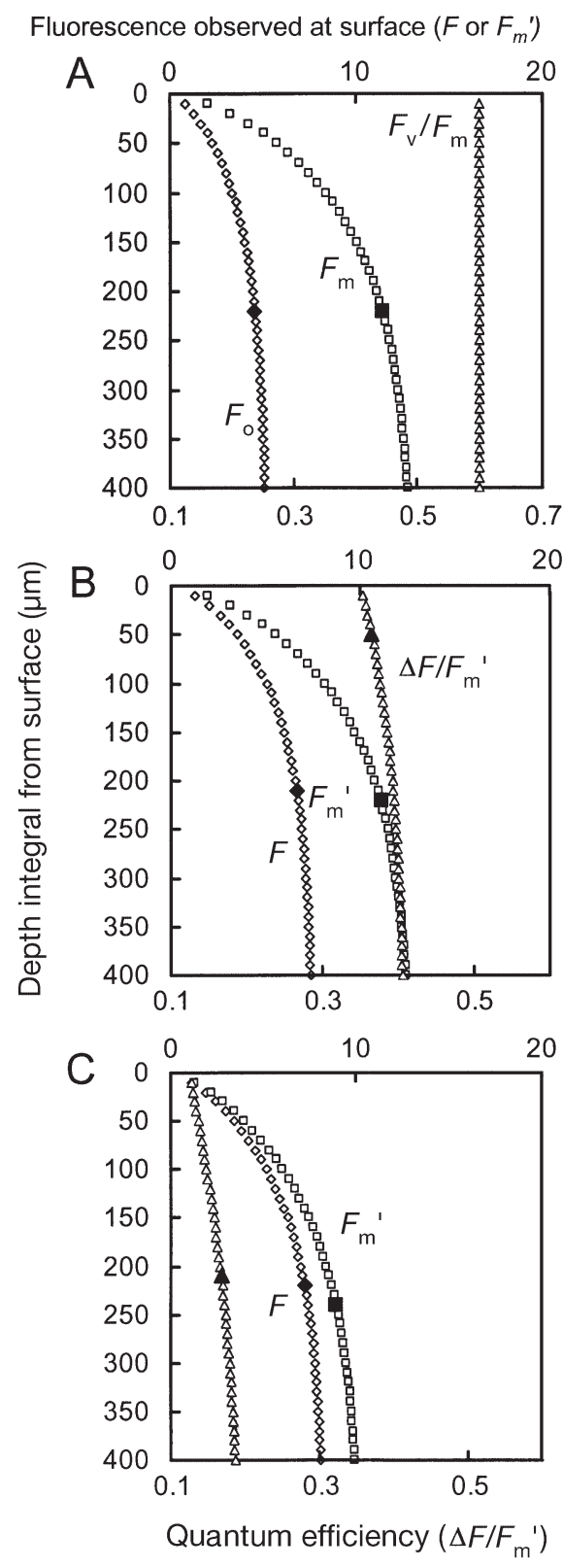

Fig. 5. Contribution of signals from increasing depth intervals to the fluorescence parameters measured at the surface. The cumulative values for $F(\diamond), F_{\mathrm{m}}{ }^{\prime}(\square)$ and $\Delta F / F_{\mathrm{m}}{ }^{\prime}(\Delta)$ were calculated for increasingly deeper depth intervals. Model runs were made in (A) darkness or (B) at surface irradiances of 500 and (C) $2000 \mu \mathrm{mol}$ photon $\mathrm{m}^{-2} \mathrm{~s}^{-1}$. $F$ and $F_{\mathrm{m}}$ ' are plotted on the upper axis and photochemical efficiency $\left(\Delta F / F_{\mathrm{m}}{ }^{\prime}\right)$ is plotted on the lower axis. Filled symbols represent the point at which a cumulative value has reached $90 \%$ of its final value 


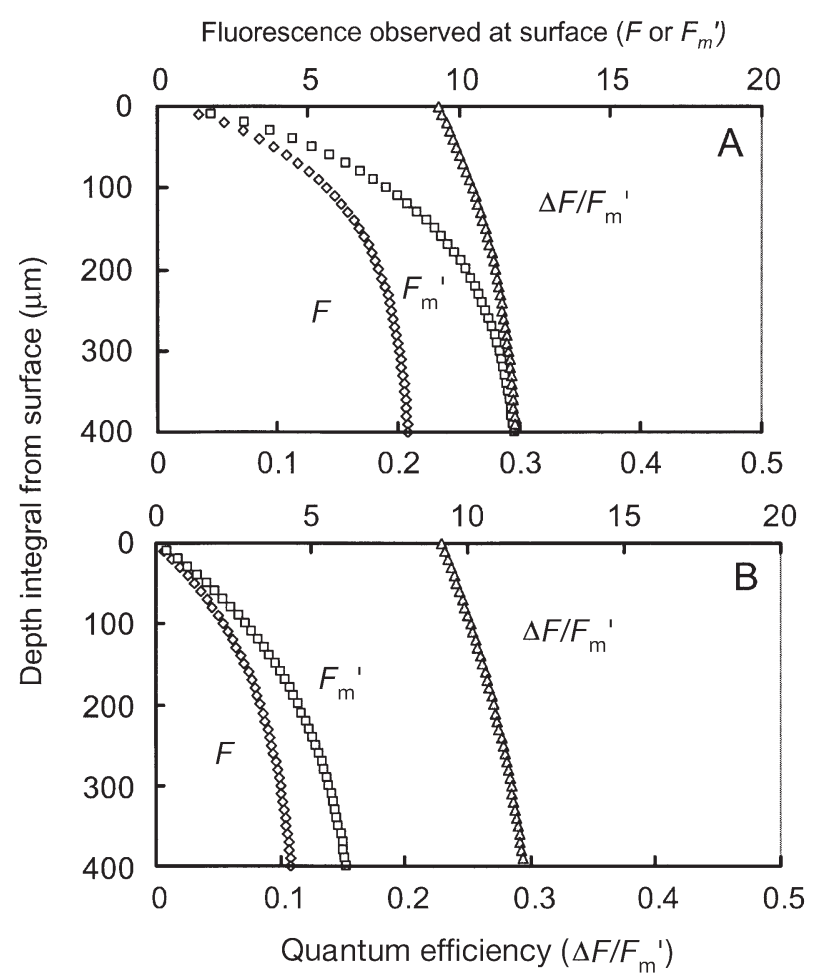

Fig. 6. Effect of changing the distribution of microalgal chlorophyll with depth on observed, depth-integrated fluorescence parameters at the surface. At a set actinic irradiance of $1000 \mu \mathrm{mol}$ photon $\mathrm{m}^{-2} \mathrm{~s}^{-1}$, the cumulative values for $F(\diamond)$, $F_{\mathrm{m}}{ }^{\prime}(\square)$ and $\Delta F / F_{\mathrm{m}}{ }^{\prime}(\Delta)$ were calculated for increasingly deeper depth intervals for (A) the 'BS' profile and (B) the 'UNI' profile

inherent value at the sediment surface of 0.349 . This difference in photochemical yield was due to attenuation of irradiance within the first depth interval of the model, which reduced the irradiance from 500 to $485 \mu \mathrm{mol}$ photon $\mathrm{m}^{-2} \mathrm{~s}^{-1}$, leading to a higher $\Delta F / F_{\mathrm{m}}{ }^{\prime}$. The value for $\Delta F / F_{\mathrm{m}}{ }^{\prime}$ when summed over all depths from 0 to $400 \mu \mathrm{m}$ was higher again, at 0.406 , which is $14 \%$ higher than the value of 0.355 for cells in the surface 0 to $10 \mu \mathrm{m}$ layer. Surface irradiance was then increased to a value similar to highest values recorded in the natural situation in northern Europe, $2000 \mu \mathrm{mol}$ photon $\mathrm{m}^{-2} \mathrm{~s}^{-1}$ (own long-term PAR measurements 1993 to 2004). Whilst $90 \%$ of the asymptotic values of $F$ and $F_{\mathrm{m}}{ }^{\prime}$ were again achieved within the upper $240 \mu \mathrm{m}$ of the sediment, there was now an increase in the depth integration required to produce an asymptotic value of $\Delta F / F_{\mathrm{m}}$ '. With the higher irradiance, there was a $46 \%$ difference between the depth integrated value of 0.187 and the surface 0 to $10 \mu \mathrm{m}$ layer value of 0.128 (Fig. 5C). Therefore, apparent electron transport rates calculated using Eq. (3) would also be $46 \%$ higher than the inherent value of rETR at this maximum irradiance. The differences between the inherent and depth- integrated fluorescence estimates of photosynthetic efficiency may thus be minor or large, depending on the irradiance level at the sediment surface. At irradiances $<2 \times E_{\mathrm{k}}$, differences between inherent and depth-integrated measurements of variable fluorescence will be negligible.

In the next simulation, the effect of a rearrangement of the algal cells within the sediment was tested. During daytime low tides, benthic diatoms move to the surface of the sediment shortly after emersion to form a maximum cellular concentration at the surface. Migration back down into the sediment occurs shortly before the incoming tide returns. The result is the daytime and night-time profiles of chl a differ markedly (de Brouwer \& Stal 2001), with chl a being distributed evenly throughout the sediment during darkness. An uniform chl a profile may also occur after intense bioturbation or after physical disturbance by heavy rainfall of the upper sediment layers. Total chl a within the upper $2 \mathrm{~mm}$ was constant in the 'BS' and 'UNI' profiles used in this simulation (Table 1) but the distribution of pigment with depth was altered (Fig. 1). Irradiance was set to $1000 \mu \mathrm{mol}$ photon $\mathrm{m}^{-2} \mathrm{~s}^{-1}$. The most striking effect of a shift in chl a distribution, from the exponentially decreasing 'BS' to the uniformly distributed 'UNI', was a reduction in the total $F$ and $F_{\mathrm{m}}$ ' fluorescence values for the latter profile (Fig. 6). The steadystate fluorescence level $F$ was reduced from 8.3 to 4.3 due to chl a being redistributed to deeper layers beyond the range of the fluorescence sensor (Table 3). The photochemical yield was much less affected by the shift in distribution of chl a. $\Delta F / F_{\mathrm{m}}{ }^{\prime}$ in the surface $10 \mu \mathrm{m}$ layer of the 'BS' profile was 0.232 at $1000 \mu \mathrm{mol}$ photon $\mathrm{m}^{-2} \mathrm{~s}^{-1}$; this was increased by $28 \%$ to 0.296 by integration over all depths (Fig. 6A). The 'UNI' profile had a surface $10 \mu \mathrm{m}$ value of 0.230 , which was increased to 0.302 by including fluorescence from all depths (Fig. 6B). Thus, the apparent electron transport rate measured at this irradiance would be higher than the inherent rate but apparent ETR would differ by less than $2 \%$ as the abundance of microphytobenthic cells was switched between 2 profiles, which are indicated by the microscale-slicing technique to be most commonly found in the field situation.

However, the complete migration of all algal cells to the surface, as indicated by low temperature scanning electron micrography, creates a different optical situation. Within a surface biofilm, with all available space occupied by tightly packed algal cells, photons are only absorbed by pigments and attenuation by the non-biological sediment component plays no role. When the 'SSL' unicellular layer profile was used in the model, at a surface irradiance of $1000 \mu \mathrm{mol}$ photon $\mathrm{m}^{-2} \mathrm{~s}^{-1}$, the resultant depth-integrated photochemical efficiency was 0.277 . The $19 \%$ deviation between this 
Table 3. Summary of apparent fluorescence parameters from the chl a depth profiles tested in this study. $F$ and $\Delta F / F_{\mathrm{m}}$ ' were calculated with an actinic irradiance of $1000 \mu \mathrm{mol}$ photon $\mathrm{m}^{-2} \mathrm{~s}^{-1}$ and a low level of non-photochemical quenching (maximum NPQ $=0.5$ ). The inherent photochemical efficiency at this irradiance was 0.227 . The percentage differences with respect to the 'BS' profile are shown. $F_{\mathrm{o}}$ was calculated in the absence of irradiance, and $F_{\mathrm{o}} / \mathrm{Chl}$ is the ratio of $F_{\mathrm{o}}$ fluorescence to chlorophyll $a$ in the upper $2 \mathrm{~mm}$ of the sediment model. The units of $F$ and $F_{0}$ represent the signal which would be recorded by an integrating fluorometer

\begin{tabular}{|lcccccc|}
\hline & KY & BS & UNI & MSL & SUB & SSL \\
\hline$F$ & 14.8 & 8.3 & 4.3 & 22.3 & 13.8 & 14.2 \\
$\Delta F / F_{\mathrm{m}}{ }^{\prime}$ & 0.309 & 0.296 & 0.293 & 0.330 & 0.363 & 0.277 \\
$\%$ difference & 4 & 0 & -1 & 11 & 23 & -6 \\
$F_{\mathrm{o}}$ & 8.6 & 5.1 & 2.7 & 14.2 & 9.5 & 8.6 \\
$F_{\mathrm{o}} / \mathrm{Chl}_{(0-2000 \mu \mathrm{m})}$ & 0.05 & 0.06 & 0.03 & 0.07 & 0.05 & 0.30 \\
\hline
\end{tabular}

The increase in apparent photochemical efficiency caused by biofilm formation at the surface was accompanied by increases in the absolute levels of fluorescence at $F$ and $F_{\mathrm{m}}{ }^{\prime}$ (Table 3 ). In contrast, migration downwards of a biofilm from the 'MSL' to 'SUB' positions was marked by a decrease in $F$. However, the use of fluorescence levels to predict changes in the quantity of surface chlorophyll must be done with caution due to the strong ability of microphytobenthic diatoms to induce changes in the level of $F$ and $F_{\mathrm{m}}{ }^{\prime}$ via other means, namely by the induction of non-photochemical quenching. value and the other 0 to $10 \mu \mathrm{m}$ values stated above (for 'BS' and 'UNI', 0.230 to 0.232 ) was due to the strong attenuation of PAR within the algal biofilm. The irradiance at a depth of $10 \mu \mathrm{m}$, after passage through the simulated unicellular biofilm, was reduced to $556 \mu \mathrm{mol}$ photon $\mathrm{m}^{-2} \mathrm{~s}^{-1}$. When the density of cells at the sediment surface was increased by using the 'MSL' model, whilst holding all other parameters constant, the apparent photochemical efficiency increased to 0.330 . Simulating a mass downward migration of algal cells by changing the position of the thick biofilm to a layer located 100 to $150 \mu \mathrm{m}$ below the surface resulted in a further increase in the measured efficiency to 0.356 . Thus, depending upon the physical arrangement of the sediment and algal cells, photochemical efficiency measured by a modulated fluorometer above a sediment sample illuminated with $1000 \mu \mathrm{mol}$ photon $\mathrm{m}^{-2}$ $\mathrm{s}^{-1}$ will vary in a limited range from -6 to $23 \%$ of the value obtained with the 'BS' profile (Table 3 ). The overestimation of photochemical efficiency with regard to the inherent value was larger, ranging from $22 \%$ for 'SML' to $60 \%$ for the 'SUB' model at this irradiance. Differences between the inherent photochemical efficiency of the algal cells and the 'apparent' efficiency observed by a PAM fluorometer measuring the integral signal at the sediment surface were thus more pronounced when an optically dense biofilm was present. The differences in yields and in electron transport rates between different optical arrangements of the sediment were in all cases increased by exposure to a higher irradiance (Fig. 7). The inherent relationship between ETR and $E$ showed saturation at high irradiances, so that increasing irradiance did not result in further increases in ETR. In contrast, the ETR versus E curves calculated for the apparent responses showed only varying degrees of saturation (Fig. 7B). The 'SUB' model in particular showed increasing ETR with irradiance throughout the whole range of irradiances.
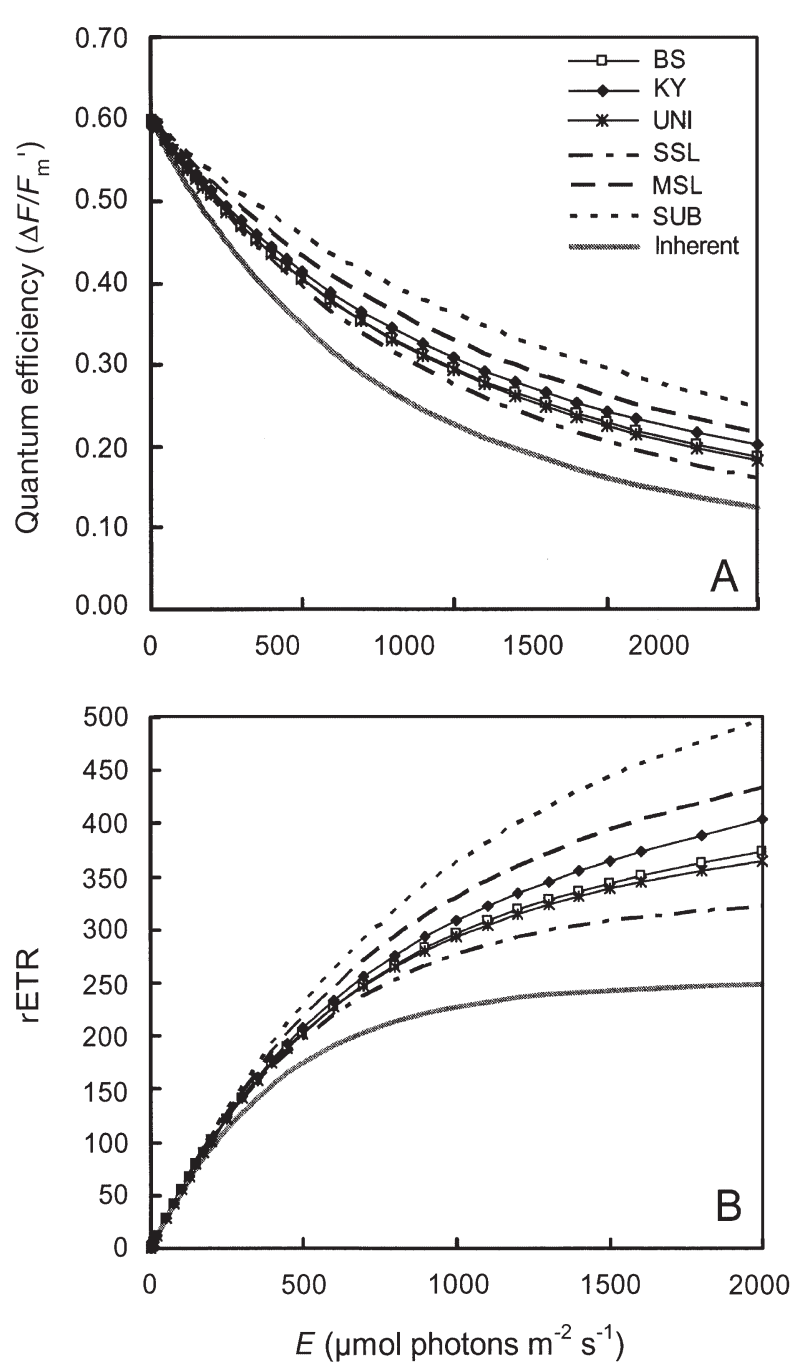

Fig. 7. Comparison of inherent and apparent fluorescence parameters for all chl a depth profiles used in the sedimentoptical model. The solid line shows the inherent relationship between incident irradiance and (A) $\Delta F / F_{\mathrm{m}}$ ' and (B) rETR which was used as a forcing function for the model 


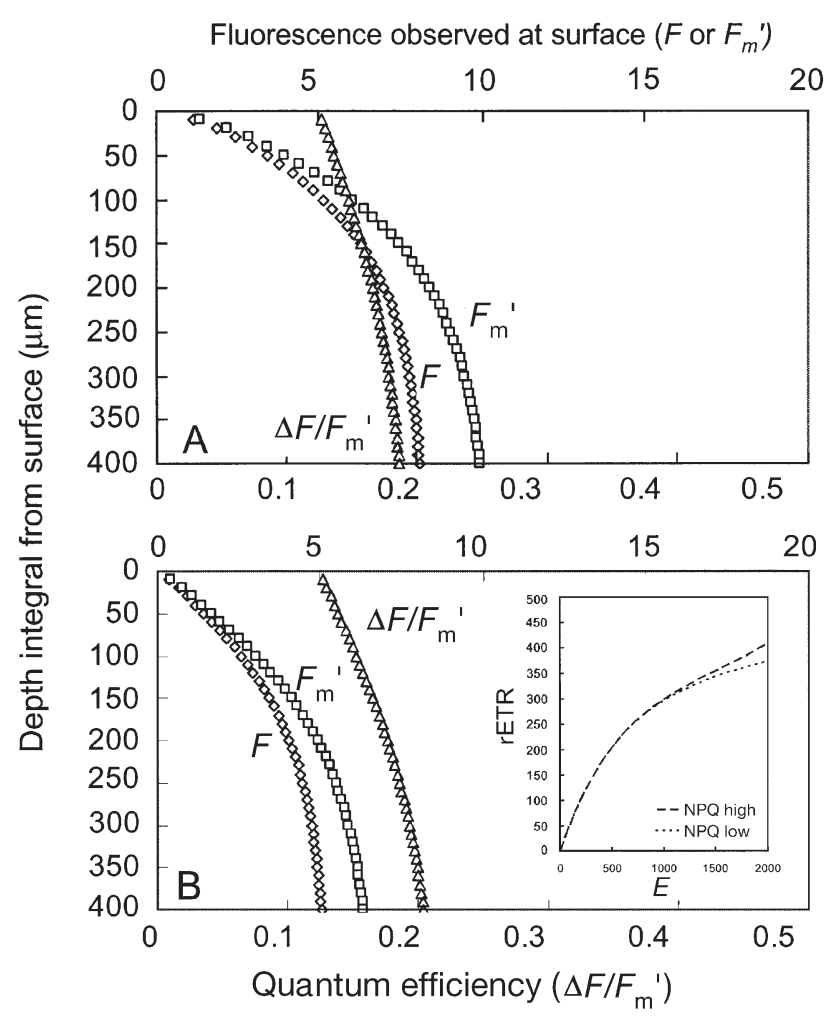

Fig. 8. Effect of non-photochemical quenching (NPQ) on the apparent fluorescence parameters measurable at the sediment surface for the 'BS' model profile. Actinic irradiance was set to $2000 \mu \mathrm{mol}$ photon $\mathrm{m}^{-2} \mathrm{~s}^{-1}$, and the cumulative values for $F(\diamond), F_{\mathrm{m}}{ }^{\prime}(\square)$ and $\Delta F / F_{\mathrm{m}}{ }^{\prime}(\Delta)$ were calculated for increasingly deeper depth intervals. NPQ was set to either (A) low or (B) high levels according to the responses shown in Fig. 4. Inset: relationship between ETR and $E$ for all irradiances between 0 and $2000 \mu \mathrm{mol}$ photon $\mathrm{m}^{-2} \mathrm{~s}^{-1}$ at low and high NPQ

Chlorophyll fluorescence quenching can occur in diatoms when high surface irradiances are combined with adverse conditions for photosynthetic electron transport. This may occur during extreme temperatures (Serôdio et al. 2001) or be due to limitation by the supply of dissolved inorganic carbon to a biofilm. The effect is most prominent in the surface layers, where the highest irradiance is found. Here, the levels of $F$ and $F_{\mathrm{m}}{ }^{\prime}$ can be reduced by over 50 and $70 \%$, respectively, relative to the unquenched levels, thus decreasing their contribution to the overall fluorescence signal and increasing the relative contribution of fluorescence from deeper in the sediment to the overall signal at the surface (Fig. 8). To test the effects of NPQ, the model was run with the 'BS' profile exposed to $2000 \mu \mathrm{mol}$ photon $\mathrm{m}^{-2} \mathrm{~s}^{-1}$. The depth-integrated photochemical efficiency at this irradiance, in the absence of quenching, was 0.187 . The apparent photochemical efficiency was increased to 0.210 by changing the NPQ setting to 4.0
(Fig. 4) and the absolute value of $F$ was decreased by $39 \%$. Thus, the effect of a high-irradiance induced NPQ on the fluorescence parameters $F$ and $\Delta F / F_{\mathrm{m}}{ }^{\prime}$ is optically inseparable from that of a downward migration. The shape of the ETR versus $E$ relationship was changed noticeably by the induction of NPQ at irradiances above $1000 \mu \mathrm{mol}$ photon $\mathrm{m}^{-2} \mathrm{~s}^{-1}$ (Fig. 8B inset), with the appearance of an upward turn in the curve.

The response of the apparent fluorescence yield to changes in the attenuation coefficient for nonbiological components was analysed. Whereas the chlorophyll-specific attenuation due to microalgal material is well-defined both in the literature for phytoplankton species and in our own laboratory for microphytobenthos, the non-biological attenuation factor is less well known and may vary between sediment types. A sensitivity analysis was performed using the 'BS' profile and by varying the value of $k^{*}{ }_{d(s e d)}$ to give non-biological attenuation which spanned the range of values known from the literature, 0.5 to $16 \mathrm{~mm}^{-1}$. Apparent ETR was calculated for a series of increasing irradiances and the resultant ETR-E curves were fit with Eq. (5) (Fig. 9). The effect of increasing sediment attenuation on light-limited photosynthesis $\left(\alpha_{\text {ETR }}\right)$ was slight but there was an $11 \%$ increase in light-saturated ETR as $k_{\mathrm{d}(\text { sed })}$ was increased from 0.5 to $5 \mathrm{~mm}^{-1}$. Thereafter, ETR $\mathrm{Emax}_{\operatorname{man}}$ declined slightly as attenuation was increased further.

\section{DISCUSSION}

Our attempt to validate the use of the variable fluorescence method for measurement of photosynthetic rates on intertidal soft sediments relies on an accurate assessment of the irradiance field within the sediment.

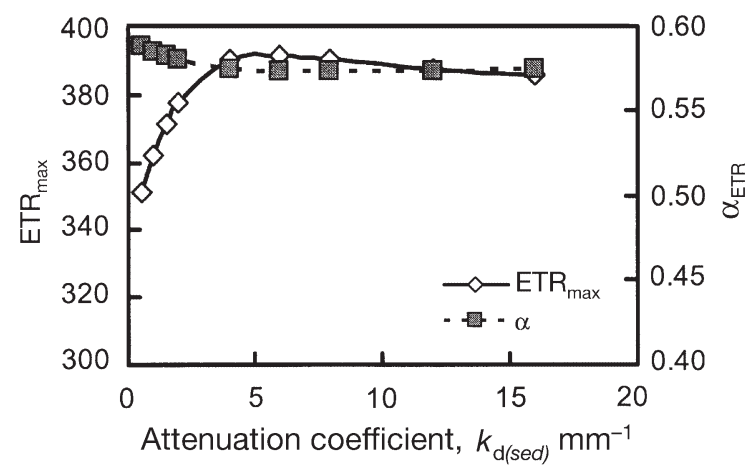

Fig. 9. Sensitivity analysis of the sediment-optical model. The calculation of apparent light-saturated electron transport rate $\left(E R_{\max }\right)$ and efficiency of light-limited photon utilisation $\left(\alpha_{\text {ETR }}\right)$ were calculated after varying the attenuation coefficient for non-biological material, $k_{\mathrm{d}(\text { sed })}$. The chlorophyll profile used in this case was 'BS' 
In order to accomplish this, the most recent information on sediment composition has been combined with best estimates of the attenuation due to individual components. The model follows the Lambert-Beer law, which is valid for complex optical structures only when absorption is several times larger than scattering. The low level of reflected irradiance from estuarine mudflats (Hakvoort et al. 1997, Paterson et al. 1998) and our own measurements of irradiance versus depth profiles indicate that this assumption is valid. More highly scattering sandy sediments will require a different modeling approach, for example using Kubelka-Munk theory (Björn 1996).

Benthic microalgae, as well as being the prime objects of interest in this study, are also an important part of the sediment optical system. Benthic diatom cells range in size from 10 to $200 \mu \mathrm{m}$ and are heavily pigmented, giving a high optical density. Microspectrophotometric measurements have shown that individual algal cells of this type can absorb between 30 to $80 \%$ of the incident irradiance (Iturriaga et al. 1988), in agreement with our cellular chlorophyll-based model. The positioning and concentration of the microalgal cells in the sediment is of great importance for understanding the propagation of both actinic irradiance and the measuring light of a fluorometer, as well as for determining the primary production and ecological function of the system (Pinckney \& Zingmark 1991).

Several approaches to the reconstruction of chl a profiles with depth have been presented here. It is clear that mobile epipelic diatom cells move upwards to the photic zone of the sediment during daytime aerial exposure, but the exact positioning of the cells within the sediment is uncertain. Fine scale sectioning of frozen sediments collected during daytime low tides show convincingly that estuarine sediments have exponential decreases in chl $a$, with slope coefficients varying from 1.2 to $54 \times 10^{-4}$ (de Brouwer \& Stal 2001, Kelly et al. 2001, Perkins et al. 2003). In contrast, electron micrographs of freeze-fractured sediments have shown dense aggregations of cells in a biofilm located entirely at the sediment surface, with few cells visible within the sediment matrix (Paterson 1995, Taylor \& Paterson 1998). The actual distribution of algal biomass in any sediment at any given time will depend upon factors such as the species composition, speed and direction of migration in response to tide and time, and the rate of bioturbation due to burrowing animals.

For the biofilm models, 'MSL', 'SSL' and 'SUB', the maximum change in irradiance occurred within a depth interval smaller than the size of spherical irradiance microsensors (Kühl \& Jørgensen 1992), indicating that there are limits of this technique for providing attenuation coefficients. Thus, irradiance fields in estuarine sediments, which invariably contain highly uneven distributions of microalgal chl $a$, can best be summarized using a combination of direct measurements and a numerical simulation approach with an explicit description of the chlorophyll-depth profile. The attenuation coefficient used in the model, $k_{\mathrm{d}(\text { sum) }}$, was dependent upon the choice of depth interval in the model runs with heterogeneous pigment profiles. The resultant values were highest in depth intervals with a high chl a. Other authors have assumed a uniform profile of chl a with depth, with measured $k_{\mathrm{d}(\mathrm{sum})}$ values for actinic irradiance ranging from $3.4 \mathrm{~mm}^{-1}$ (Kühl \& Jørgensen 1994) to $17 \mathrm{~mm}^{-1}$ (Serôdio et al. 1997, 2001). This approach is unlikely to provide an accurate simulation of the within-sediment irradiance field for the examples discussed here.

The model runs showed that although the actual penetration depth of the fluorometer beam was shallow $\left(<400 \mu \mathrm{m}_{\text {; }}\right.$ in agreement with previous publications by Kromkamp et al. 1998 and Serôdio et al. 2001), the variable fluorescence parameter $\Delta F / F_{\mathrm{m}}{ }^{\prime}$, as measured by a fluorometer viewing the irradiance leaving a sediment surface was not equal to the inherent photosynthetic efficiency of algal cells in the assemblage. The apparent $\Delta F / F_{\mathrm{m}}^{\prime}$ was always higher than the inherent one due to the influence of fluorescence from deeper sediment layers, with the effect being most pronounced at high irradiances and when non-photochemical quenching was strongly induced. The overestimation of $\Delta F / F_{\mathrm{m}}{ }^{\prime}$ was lowest for the most simple optical situation, which occurred when a single layer of algal cells was positioned at the sediment surface. The largest overestimation was for the most complex situation where a thick algal layer was postulated to be at an intermediate irradiance, 100 to $150 \mu \mathrm{m}$ below the sediment surface.

There was good agreement in apparent fluorescence yields between the 3 model runs which used uniform or exponential fits of chl a versus depth (Fig. 7). If these profiles are indeed the most similar to those found in muddy estuarine sediments, then this result suggests that although the variable fluorescence method will always overestimate the inherent electron transport rate, there will be little effect of changing pigment profiles on the apparent ETR.

However, there was a greater range of variation in the surface-integrated ETR estimates derived from the 3 biofilm simulations, 'SSL', 'MSL' and 'SUB' (Fig. 7, Table 3). Thus, if densely populated biofilms are indeed commonly found in the natural environment, then interpretation of the apparent fluorescence yield will require further knowledge of the sediment structure. This information can perhaps best be obtained with quantitative electron micrography of freeze fracture surfaces taken immediately after chlorophyll fluorescence measurements. 
The overestimation of apparent ETR with respect to inherent ETR was most severe when a wide range of actinic irradiances were present within the depth sampled by the fluorometric measuring beam. The fluorometer was then 'sampling' a population of algal cells displaced throughout a steep irradiance gradient. This situation occurred in sediments with a high nonbiological attenuation and within dense biofilms. In these cases, plots of ETR versus $E$ show a nonsaturating curve and curves of this type have also been measured on natural samples under certain conditions (Kromkamp et al. 1998, Fig. 5).

Overestimation of apparent ETR was exacerbated by non-photochemical quenching, although the effect was in most cases small. At very high irradiances, this resulted in a decrease of the contribution to overall fluorescence by the cells at the sediment surface. The non-linear induction of NPQ with increasing irradiance resulted in ETR versus $E$ curves with distinct inflexions. Such S-shaped curves have occasionally been observed by us during field measurements of intact sediments and have been reported in the literature (Perkins et al. 2002). They may occur as a result of NPQ-induction or may be due to other external factors such as increasing photosynthetic activity, as increasing irradiance warms the sediment surface (Blanchard et al. 1996).

Serôdio (2003) showed that the exact value of photosynthetic efficiency was not the primary determinant of integrated sediment production. Rather, the combination of irradiance and photosynthetically active biomass (PAB) together with a measure of efficiency such as $\Delta F / F_{\mathrm{m}}{ }^{\prime}$ can be combined to give the best explanation of observed production rates. A sum parameter of irradiance $\times$ biomass $\times$ photosynthetic rate can be simply constructed using the term $\Delta F / F_{\mathrm{m}}{ }^{\prime} \times E \times F_{\mathrm{o}}$. This composite parameter was compared with calculated rates of primary production derived from the sediment optical model by integration of photosynthesis over the whole photic zone (e.g. gross microphytobenthic primary production, $\Sigma$ PP). The sum term showed a direct proportionality to $\Sigma \mathrm{PP}$ for the models, 'UNI', 'KY' and 'BS' with all points falling close to the same line (Fig. 10). This confirms the findings of Serôdio (2003), who found a close relationship between measured primary production with oxygen evolution and the term $\Delta F / F_{\mathrm{m}}{ }^{\prime} \times E \times F_{\mathrm{o}}$. However, the ratio of $\Sigma \mathrm{PP}$ to $\Delta F / F_{\mathrm{m}}{ }^{\prime} \times E$ $\times F_{\mathrm{o}}$ was not the same for all models, as shown by the 3 plots for the 3 biofilm profiles (Fig. 10). In the case of the 'SUB' model, the value of the specific attenuation coefficient $k^{*} \mathrm{~d}($ sed $)$ determined the slope of the relationship between $\Sigma \mathrm{PP}$ and $\Delta F / F_{\mathrm{m}}{ }^{\prime} \times E \times F_{\mathrm{o}}$, showing again that knowledge of sediment structure can be important. Thus, the apparent electron transport rate as measured by a fluorometer measuring the integrated sediment fluorescence can potentially be very useful for estimating primary production when combined with a measure of PAB. Further calibrations on a range of sediment types will be required to confirm this.

PAB can be estimated in a number of ways, for example by destructive sampling with the cryolander technique or via optical parameters (Barranguet \& Kromkamp 2000, Honeywill et al. 2002). The results of the modeling exercise here suggest that the relationship between absolute fluorescence, e.g. $F$ or $F_{\mathrm{o}}$ and chl $a$ is highly dependent upon the choice of microalgal depth profile (Table 3 ). Field measurements of $F_{\mathrm{o}}$ versus chl a from the upper layer of the sediment show the opposite, that a tight correlation exists between the 2 measures (Honeywill et al. 2002). This result, which was present over several seasons suggests that, in the natural environment, a limited range of sediment pigment profiles are present during low tide samplings. Similar findings were observed in the model of Serôdio et al. (2001), who then proposed the use of absolute chlorophyll fluorescence values as an estimator of PAB. However, chlorophyll fluorescence may not always be the best choice of parameter, due to the expense of measuring equipment and the strong dependence of fluorescence signal on machine-specific parameters such as detector gain. It is also difficult to separate the effects of vertical migration from those of non-photochemical quenching on the observed fluorescence

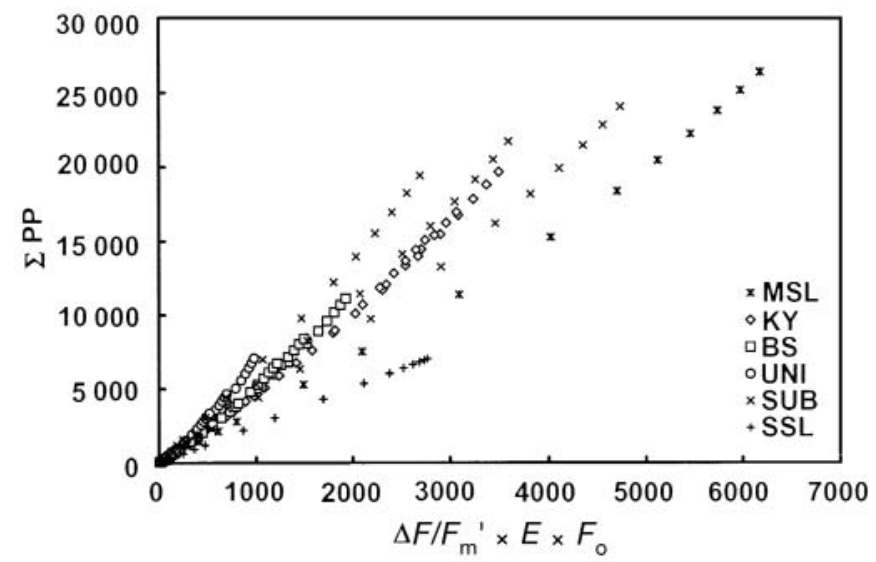

Fig. 10. Comparison of calculated gross sediment primary production $(\Sigma \mathrm{PP})$ and estimated primary production using the sum parameter $\Delta F / F_{\mathrm{m}}{ }^{\prime} \times E \times F_{\mathrm{o}}$ (Serôdio 2003). $\Sigma \mathrm{PP}$ was calculated by integrating the rate of photosynthetic electron flow $\left(\mathrm{e}^{-} \mathrm{m}^{-3} \mathrm{~s}^{-1}\right)$ at each depth interval from the sediment surface to the bottom of the photic zone and would be proportional to the amount of carbon fixation or oxygen evolution by the sediment if the stochiometry of $\mathrm{e}^{-}$/fixed $\mathrm{C}$ was known. Models were run with combinations of surface irradiance from 1 to $2000 \mu \mathrm{mol}$ photon $\mathrm{m}^{-2} \mathrm{~s}^{-1}$ and $k_{\mathrm{d}(\text { sed })}$ from 2 to $6 \mathrm{~mm}^{-1}$ for each of the $6 \mathrm{chl}$ a depth profiles. For the 'SUB' profile, changing the attenuation coefficient produced 3 distinct sets of points but for the other profiles this effect was not apparent 
signal as shown here. Other optical parameters are available such as the measurement of reflected irradiance from the sediment surface, which contains a characteristic spectral signature from microphytobenthic algae (Paterson et al. 1998). With careful selection of wavelengths, this method should also be related directly to pigment concentration (Méléder et al. 2003) and will prove to be equally useful in the assessment of PAB.

In conclusion, it should be stressed that the situation in intertidal sediment biofilms is theoretically not different from the situation in leaves or macroalgae, where it cannot be ruled out that the underlying parenchymal cells will add to the apparent fluorescence together with the upper epidermis cells. In these situations, the variable fluorescence method as a means to measure photosynthetic electron transport has been validated many times (Genty et al. 1989, Seaton \& Walker 1990). The aim of this paper was to clarify the relationships between inherent and apparent fluorescence parameters and to validate the variable fluorescence technique for use in situ. It should be realized that all biological assays suffer to some degree from limitations. For example, the radiocarbon method is extremely difficult to apply to intact sediment cores due to the rapid disappearance of radiolabel within the narrow, highly active sediment photic zone (Vadeboncoeur \& Lodge 1998). Yet, this method has been chosen as a benchmark method against which the chlorophyll fluorescence method was compared (Perkins et al. 2002). It has been shown here that the rate of photosynthesis estimated via fluorescence does indeed depend upon the optical characteristics of the sediment. However, the differences between apparent rates are not large and, in any case, the total primary production of microphytobenthic algae is determined by a combination of irradiance, temperature and pigment concentration (Serôdio 2003), rather than primarily by photosynthetic parameters. Thus, in answer to the criticisms of previous authors, yes, integrating chlorophyll fluorometers can still be used to estimate the rate of photosynthetic electron transport within microphytobenthic biofilms.

Acknowledgements. This work was funded by the EU program number EVK3-CT-2001-00052 'A system of hierarchical monitoring methods for assessing changes in the biological and physical state of intertidal areas'. This is NIOO-KNAW publication number 3484 .

\section{LITERATURE CITED}

Barranguet C, Kromkamp J (2000) Estimating primary production rates from photosynthetic electron transport in estuarine microphytobenthos. Mar Ecol Prog Ser 204:39-52
Behrenfeld MJ, Falkowski PG (1997) Photosynthetic rates derived from satellite-based chlorophyll concentration. Limnol Oceanogr 42:1-20

Björn LO (1996) Light propagation in biological materials and natural waters. Sci Mar 60(S):9-17

Blanchard GF, Guarini JM, Gros P, Richard P (1997) Seasonal effect on the relationship between the photosynthetic capacity of intertidal microphytobenthos and temperature. J Phycol 33:723-728

Colijn F, Kraay GW, Duin RNM, Tillmann U, Veldhuis MJW (1996) Design and test of a novel $P_{\max }$ incubator to be used for measuring the primary production in ICES monitoring studies. ICES CM 1996/L3

de Brouwer JFC, Stal LJ (2001) Short-term dynamics in microphytobenthos distribution and associated extracellular carbohydrates in surface sediments of an intertidal mudflat. Mar Ecol Prog Ser 218:33-44

de Jong DJ, de Jonge VN (1995) Dynamics and distribution of microphytobenthic chlorophyll $a$ in the western Scheldt estuary (SW Netherlands). Hydrobiologia 311:21-30

de Jong L, Admiraal W (1984) Competition between three estuarine benthic diatom species in mixed cultures. Mar Ecol Prog Ser 18:269-275

Decho AW, Kawaguchi T, Allison MA, Louchard EM and 5 others (2003) Sediment properties influencing upwelling spectral reflectance signatures: The 'biofilm gel effect'. Limnol Oceanogr 48:431-443

Dodds WK, Biggs BJF, Lowe RL (1999) Photosynthesis-irradiance patterns in benthic microalgae: Variations as a function of assemblage thickness and community structure. J Phycol 35:42-53

Flameling I, Kromkamp J (1998) Light dependence of quantum yields for PSII charge separation and oxygen evolution in eucaryotic algae. Limnol Oceanogr 43:284-297

Flemming BW, Delafontaine MT (2000) Mass physical properties of muddy intertidal sediments: some applications, misapplications and non-applications. Cont Shelf Res 20: 1179-1197

Genty B, Briantais JM, Baker NR (1989) The relationship between the quantum yield of photosynthetic electron transport and quenching of chlorophyll fluorescence. Biochim Biophys Acta 990:87-92

Glud RN, Kühl M, Wenzhofer F, Rysgaard S (2002) Benthic diatoms of a high Arctic fjord (Young Sound, NE Greenland): importance for ecosystem primary production. Mar Ecol Prog Ser 238:15-29

Guarini JM, Blanchard GF, Gros P, Gouleau D, Bacher C (2000) Dynamic model of the short-term variability of microphytobenthic biomass on temperate intertidal mudflats. Mar Ecol Prog Ser 195:291-303

Hakvoort HWJ, Heymann K, Stein C, Murphy D (1997) In situ optical measurements of sediment type and phytobenthos of tidal flats: a basis for imaging remote sensing spectroscopy. Dtsch Hydrogr Z 49:1-7

Henley WJ (1993) Measurement and interpretation of photosynthetic light-response curves in algae in the context of photoinhibition and diel changes. J Phycol 29:729-739

Hofstraat JW, Peeters JCH, Snel JFH, Geel C (1994) Simple determination of photosynthetic efficiency and photoinhibition of Dunaliella tertiolecta by saturating pulse fluorescence measurements. Mar Ecol Prog Ser 103:187-196

Honeywill C, Paterson DM, Hagerthey SE (2002) Determination of microphytobenthic biomass using pulse-amplitude modulated minimum fluorescence. Eur J Phycol 37:485-492

Iturriaga R, Mitchell BG, Kiefer DA (1988) Microphotometric analysis of individual particle absorption spectra. Limnol Oceanogr 33:128-135 
Jewson DH, Talling JF, Dring MJ, Tilzer MM, Heaney SI, Cunningham C (1984) Measurement of photosynthetically available radiation in freshwater: comparative tests of some current instruments used in studies of primary production. J Plankton Res 6:259-273

Kelly JA, Honeywill C, Paterson DM (2001) Microscale analysis of chlorophyll-a in cohesive, intertidal sediments: the implications of microphytobenthos distribution. J Mar Biol Assoc UK 81:151-162

Kirk JTO (1994) Light and photosynthesis in aquatic ecosystems. Cambridge University Press, Cambridge

Krause GH, Weis E (1991) Chlorophyll fluorescence and photosynthesis: the basics. Ann Rev Plant Physiol Plant Mol Biol 42:313-349

Kromkamp JC, Forster RM (2003) The use of variable fluorescence measurements in aquatic ecosystems: differences between multiple and single turnover measuring protocols and suggested terminology. Eur J Phycol 38:103-112

Kromkamp J, Barranguet C, Peene J (1998) Determination of microphytobenthos PSII quantum efficiency and photosynthetic activity by means of variable chlorophyll fluorescence. Mar Ecol Prog Ser 162:45-55

Kühl M, Jørgensen BB (1992) Spectral light measurements in microbenthic phototrophic communities with a fiberoptic microprobe coupled to a sensitive diode-array detector. Limnol Oceanogr 37:1813-1823

Kühl M, Jørgensen BB (1994) The light field of microbenthic communities: radiance distribution and microscale optics of sandy coastal sediments. Limnol Oceanogr 39:1368-1398

Kühl M, Lassen C, Jørgensen BB (1994) Light penetration and light intensity in sandy marine sediments measured with irradiance and scalar irradiance fiberoptic microprobes. Mar Ecol Prog Ser 105:139-148

Lavaud J, Rousseau B, van Gorkom HJ, Etienne AL (2002) Influence of the diadinoxanthin pool size on photoprotection in the marine planktonic diatom Phaeodactylum tricornutum. Plant Physiol 129:1398-1406

Lewis MR, Smith JC (1983) A small volume, short-incubationtime method for measurement of photosynthesis as a function of incident irradiance. Mar Ecol Prog Ser 13:99-102

Masojídek J, Grobbelaar JU, Pechar L, Koblízek M (2001) Photosystem II electron transport rates and oxygen production in natural waterblooms of freshwater cyanobacteria during a diel cycle. J Plankton Res 23:57-66

Méléder V, Barille L, Launeau P, Carrère V, Rince Y (2003) Spectrometric constraint in analysis of benthic diatom biomass using monospecific cultures. Remote Sens Environ 88:386-400

Meyercordt J, Domin A, Forster RM, Hartig P, Köhler J (1999) Intercomparison of light meters. Berichte Forsch u Technologiezentr Westküste d Univ Kiel 19:39-52

Morris EP, Kromkamp JC (2003) Inlfuence of temperature on the relationship between oxygen and fluorescence-based estimates of photosynthetic parameters in a marine benthic diatom (Cylindrotheca closterium). Eur J Phycol 38: 133-142

Paterson DA, Wiltshire KH, Miles A, Blackburn J, Davidson I, Yates MG, McGrorty S, Eastwood JA (1998) Microbiological mediation of spectral reflectance from intertidal cohesive sediments. Limnol Oceanogr 43:1207-1221

Paterson DM (1995) Biogenic structure of early sediment fabric visualised by low-temperature scanning electron

Editorial responsibility: Otto Kinne (Editor),

Oldendorf/Luhe, Germany microscope. J Geol Soc 152:131-140

Perkins RG, Oxborough K, Hanlon ARM, Underwood GJC, Baker NR (2002) Can chlorophyll fluorescence be used to estimate the rate of photosynthetic electron transport within microphytobenthic biofilms? Mar Ecol Prog Ser 228:47-56

Perkins RG, Honeywill C, Consalvey M, Austin HA, Tolhurst TJ, Paterson DM (2003) Changes in microphytobenthic chlorophyll $a$ and EPS resulting from sediment compaction due to de-watering: opposing patterns in concentration and content. Cont Shelf Res 23:575-586

Pinckney J, Zingmark R (1991) Effects of tidal stage and sun angles on intertidal benthic microalgal productivity. Mar Ecol Prog Ser 76:81-89

Round FE, Palmer JD (1966) Persistent, vertical migration rhythms in benthic microflora. II. Field and laboratory studies on diatoms from the banks of the river Avon. J Mar Biol Assoc UK 46:191-214

Schreiber U, Bilger W, Neubauer C (1994) Chlorophyll fluorescence as a nonintrusive indicator for rapid assessment of in vivo photosynthesis. In: Schulze ED, Caldwell MM (eds) Ecophysiology of photosynthesis. Springer, Berlin, p 49-70

Seaton GGR, Walker DA (1990) Chlorophyll fluorescence as a measure of photosynthetic carbon assimilation. Proc R Soc Lond Ser B 242:29-35

Serôdio J (2003) A chlorophyll fluorescence index to estimate short-term rates of photosynthesis by intertidal microphytobenthos. J Phycol 39:33-46

Serôdio J, Da Silva JM, Catarino F (1997) Nondestructive tracing of migratory rhythms of intertidal benthic microalgae using in vivo chlorophyll a fluorescence. J Phycol 33: 542-553

Serôdio J, Da Silva JM, Catarino F (2001) Use of in vivo chlorophyll a fluorescence to quantify short-term variations in the productive biomass of intertidal microphytobenthos. Mar Ecol Prog Ser 218:45-61

Taylor IS, Paterson DM (1998) Microspatial variation in carbohydrate concentrations with depth in the upper millimetres of intertidal cohesive sediments. Estuar Coast Shelf Sci 46:359-370

Underwood GJC, Kromkamp J (1999) Primary production by phytoplankton and microphytobenthos in estuaries. Adv Ecol Res 29:93-153

Vadeboncoeur Y, Lodge DM (1998) Dissolved inorganic carbon sources for epipelic algal production: sensitivity of primary production estimates to spatial and temporal distribution of ${ }^{14} \mathrm{C}$. Limnol Oceanogr 43:1222-1226

Vogelmann TC, Evans JR (2002) Profiles of light absorption and chlorophyll within spinach leaves from chlorophyll fluorescence. Plant Cell Environ 25:1313-1323

Webb WL, Newton M, Starr D (1974) Carbon dioxide exchange of Alnus rubra: a mathematical model. Oecologia 17:281-291

Wiltshire KH, Blackburn J, Paterson DM (1997) The cryolander: a new method for fine scale in situ sampling of intertidal surface sediments. J Sediment Res 67:977-981

Wolfstein K, Colijn F, Doerffer R (2000) Seasonal dynamics of microphytobenthos biomass and photosynthetic characteristics in the northern German Wadden Sea, obtained by the photosynthetic light dispensation system. Estuar Coast Shelf Sci 51:651-662

Submitted: November 6, 2003; Accepted: August 5, 2004

Proofs received from author(s): December 1, 2004 